\title{
The role of social trust in reward crowdfunding campaigns' design and success
}

\author{
Rotem Shneor $^{1}$ (1) $\cdot$ Urszula Mrzygłód ${ }^{2} \cdot$ Joanna Adamska-Mieruszewska ${ }^{2} \cdot$ Anna Fornalska-Skurczyńska $^{3}$
}

Received: 4 July 2020 / Accepted: 4 January 2021

(C) The Author(s) 2021

\begin{abstract}
Trust is critical for successful participation in online marketplaces. In crowdfunding, fundraisers seek to win the trust of potential supporters towards contributing to their projects despite risks of non-delivery or deviations from campaign promises. This study explores how cultural differences in social trust proclivities influence reward crowdfunding campaign design and success. Specifically, we analyze data about 700 campaigns from a relatively high social trust society (HTS) - Finland, and 700 campaigns from a relatively low social trust society (LTS) - Poland. We find that sharing campaign information via social media is positively associated with campaign success in both contexts. Building on the Elaboration Likelihood Model, we show that central route cues to persuasion are more prevalent in campaigns from LTS vs. HTS, and that some peripheral cues are more prevalent in campaigns from HTS than LTS. Finally, we find partial support that central route cues are more important for campaign success in LTS.
\end{abstract}

Keywords Crowdfunding $\cdot$ Trust $\cdot$ Social trust $\cdot$ Success $\cdot$ Campaign $\cdot$ Design

JEL classification M3

\section{Introduction}

Recent years have seen the proliferation of alternative finance platforms seeking to challenge and extend traditional financial services while catering to an ever wider public (Haddad and Hornuf 2019; Ziegler et al. 2020). This development came as part of the surge in financial technology (FinTech) solution

Responsible Editor: Chei Sian Lee

Rotem Shneor

rotem.shneor@uia.no

1 Department of Strategy and Management, University of Agder, School of Business and Law, Universitetsveien 19, 4630 Kristiansand, Norway

2 Department of Sustainable Market Processes, University of Gdansk, Faculty of Economics, ul. Armii Krajowej 119/121, 81-824 Sopot, Poland

3 Department of Business, IMC University of Applied Sciences Krems, Piaristengasse 1, 3500 Krems, Austria providers filling innovation gaps that were neglected by traditional institutions (Alt et al. 2018). Accordingly, fast growth was observed in the crowdfunding industry, where new types of online intermediaries facilitate exchanges and transactions between fundraisers and their backers (Méric et al. 2016; Mollick 2014). Underlying this concept is the notion that projects can be funded by pooling small sums from many contributors, instead of reliance on large contributions from a few, and that such support is raised through an open public call that is both answered and forwarded to others by members of the crowd (Belleflamme et al. 2014; Lawton and Marom 2012).

Crowdfunding models are many and involve both investment and non-investment variants (Ziegler et al. 2020). One popular model which has attracted substantial attention from both researchers and practitioners is reward crowdfunding (Shneor and Vik 2020). Under such model, backers receive non-monetary benefits in return for monetary contributions while accepting risks of non-delivery on- or deviations fromoriginal campaign pitch promises (Shneor and Munim 2019). As such, reward crowdfunding does not represent an investment per se, as it does not offer financial returns on contributions. At the same time, it does not represent a classical 
purchase either, as it involves the funding of products that are not fully developed (Zheng et al. 2018; Zvilichovsky et al. 2018), and where their delivery is marred by risks of nondelivery, late delivery, and/or other deviations from campaign promises (Appio et al. 2020; Mollick 2015). Such challenges appear in addition to uncertainties arising from spatial and temporal separation, as well as information asymmetries, which characterize online exchanges in general (Pavlou et al. 2007).

A critical aspect in mitigating risks and uncertainties in online exchanges is trust (Kim and Peterson 2017). Accordingly, a growing body of research has sought to examine the impact of different aspects of trust on crowdfunding campaign outcomes. Here, studies show that trust was positively enhancing crowdfunding contribution intentionality and behavior in both investment and non-investment crowdfunding models (Chen et al. 2014; Kang et al. 2016; Liang et al. 2019; Zhao and Vinig 2019). Furthermore, as perceived competence and ability are important dimensions of trust (Gefen 2002), it is unsurprising that other studies also showed that fundraiser credibility and reputation were positively associated with contribution intentionality, behavior, and campaigns' success (Bukhari et al. 2020; Davies and Giovannetti 2018; Li and Martin 2016; Liu et al. 2018).

However, the proclivity to trust others differs across cultures (Delhey and Newton 2005; Delhey et al. 2011; Falk et al. 2018). Moreover, social trust, at the national level, was found to be positively associated with per capita crowdfunding volumes (Ziegler et al. 2020). Hence, while the general notion that backer trust enhances likelihood of positive crowdfunding campaign outcomes may be correct, the implications of the underlying social trust conditions on crowdfunding practice in different cultural environments remain to be investigated. Figure 1 graphically presents our study at the intersection of social trust and reward crowdfunding where we set to answer the following research questions: (1) Which reward crowdfunding campaign elements are more prevalent in high vs. low trust societies?; and (2) How do these elements affect the success of reward crowdfunding campaigns in high vs. low trust societies?

For this purpose, we analyze data collected from two national reward crowdfunding platforms operating in contexts scoring differently along Delhey and Newton's (2005) social trust measure. Here, we use Finland as a relatively high trust society (hereafter 'HTS'), where $49 \%$ of sampled public indicate trusting other people, and Poland as a relatively low trust society (hereafter 'LTS'), where only $18 \%$ indicated the same (Ibid.). While these percentages have exhibited slight changes through the years, the relative position of the two cultures has remained unchanged during the forty years in which data was collected (1981-2020) as part of the World Values Survey (Haerpfer et al. 2020). Accordingly, we collected data covering 700 campaigns from Mesenaatti in Finland, and 700 campaigns from Polakpotrafi from Poland. Building on the elaboration likelihood model (hereafter 'ELM') (Petty and Cacioppo 1986), we first test for significance of differences in mean scores of measures capturing campaign elements serving as cues for central and peripheral routes to persuasion. Second, we conduct regression analyses examining the effects of such elements on both campaign success and extent of success in each market separately, and then compare the results.

Our analyses present several interesting findings. Overall, we find that thanks to differences in social trust dynamics, similar configurations of reward campaign elements may not lead to the same results in different markets. Hence campaign design and promotional strategies should accommodate different set of requirements for winning backer trust in each

Fig. 1 Positioning of study

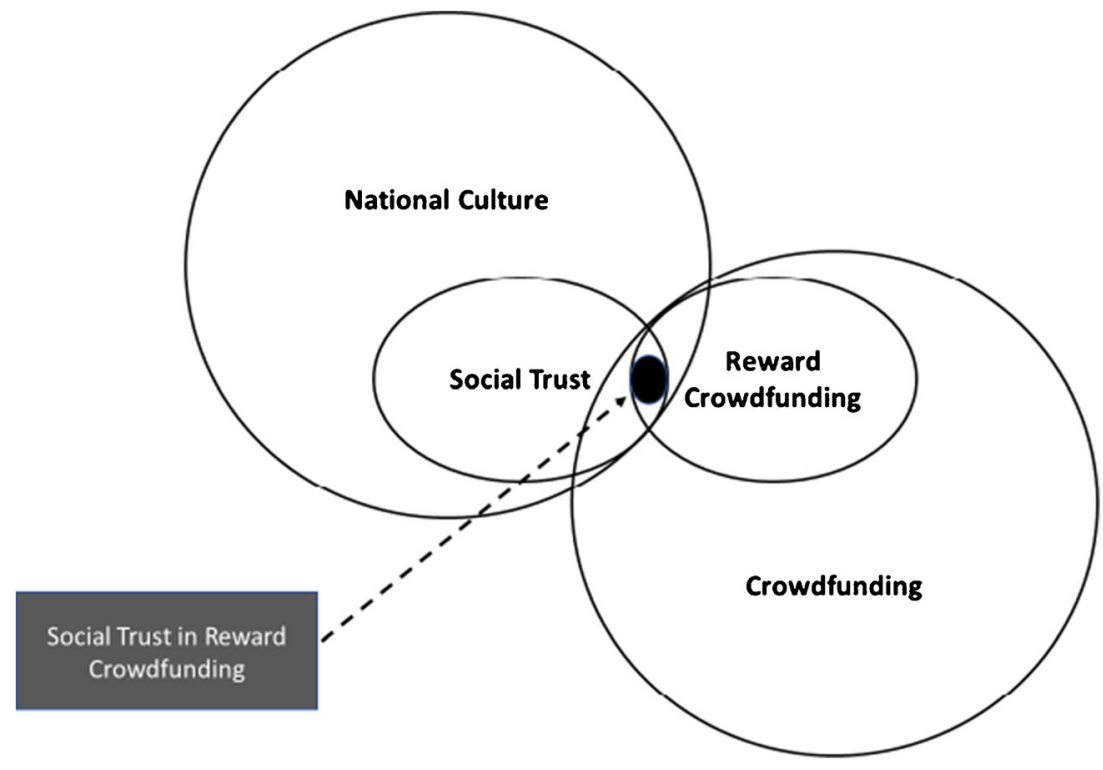


environment. First, while campaigning in HTS may require less effort in developing elements that serve as cues in a central route to backer persuasion, such investments are necessary in LTS. However, when fundraisers from HTS wish to achieve success that goes beyond reaching minimum goals, they should invest in such cues as well. Second, we show that social media engagements are critical for reward crowdfunding success regardless of the levels of social trust in a society, as they represent cues that are processed through both central and peripheral routes to persuasion. And third, we show that while some elements representing peripheral cues to persuasion are more prevalent in HTS than in LTS, they are associated with campaign success in both types of environments.

The findings are important for informing campaign design and promotional strategies, as they provide fundraisers with insights into which campaign elements should be strengthened in their persuasion efforts, based on the social trust conditions prevailing in their target markets. Furthermore, our findings can also inform platform interface design and service offerings by highlighting concrete features that may aid fundraisers in alleviating trust concerns in different social contexts. From a platform perspective, such insights may enhance their own competitive positioning by offering more socially relevant services in their home market, as well as in better preparing them for international expansion in terms of both market entry choices (i.e. when social trust conditions in market better fit existing services), or in terms of local adaptation of services (i.e. for better answering local customers' trust concerns).

In the following sections we first provide a literature review on factors impacting success and the use of persuasion and trust theories in crowdfunding success research. Next, based on conceptual linkages between trust and persuasion theory we outline a list of hypotheses for testing. A review of our methodological choices and analyses is then presented followed by a summary of our findings. A discussion comparing our findings to earlier studies is outlined while highlighting commonalities and differences, as well as the potential reasons for them. Finally, we conclude by highlighting the study's contributions, limitations, as well as implications for research and practice.

\section{Literature review}

Research on what drives crowdfunding campaign success has been booming and represents a key theme in crowdfunding research (Méric et al. 2016; Short et al. 2017). Such research seeks to inform fundraisers on considerations that may enhance the effectiveness of their campaign efforts, as well as platforms on aspects that can enhance the effectiveness of their interface and service designs (Shneor and Vik 2020).
Unsurprisingly, some literature reviews taking stock of relevant insights followed either a focus on factors impacting campaign success and outcomes (i.e. Kaartemo 2017; Shneor and Vik 2020) or on contribution and investment behavior (Hoegen et al. 2017). Here, while Kaartemo (2017) and Hoegen et al. (2017) have conducted an analysis lumping different crowdfunding models together, Shneor and Vik (2020) discussed findings with respect to each model separately.

Both studies reviewing crowdfunding success identified influential variables at the fundraiser, platform, backer/funder, and the campaign levels of analysis. Morever, the latter study also identified variables at the level of the concept/product/ service being funded, and introduced a distinction between macro (i.e. country, culture, etc.), mezzo (i.e. industry, sector, etc.) and micro (i.e. individuals, organizations, etc.) level variables. The review of factors impacting funding behavior suggested a different clustering of variables as relating to financial risk and campaign statistics, project and product quality, founder perception and attributes, social communities, context, and investor characteristics (Hoegen et al. 2017).

All literature reviews suggest variables at the campaign level of analysis as the most dominant in crowdfunding success literature. Specifically, with respect to reward crowdfunding, a recent study by Ryoba et al. (2020), which examined the predictive power of campaign success in Kickstarter, have highlighted nine indicators as providing the best result including - project description length, number of reward words, number of videos, number of updates, funding goal amount, number of reward levels, number of projects created by creators (past experience), number of projects backed by creators, and number of comments. Alternatively, the literature review by Shneor and Vik (2020) listed fourteen variables at the campaign level referring to content, crowd engagement, and campaign development dynamics, as those with the most consistent and significant associations with reward crowdfunding success across studies conducted in multiple platforms and contexts.

First, in terms of content, most of the research finds positive associations between campaign success and the use of concrete and precise language (i.e. Guo et al. 2015; Parhankangas and Renko 2017), length of campaign text (i.e. Koch and Siering 2019; Li and Martin 2016), number of updates provided by the fundraiser (i.e. Hobbs et al. 2016; Lechtenbörger et al. 2015), the inclusion of video elements (i.e. Li and Martin 2016; Mollick 2014), the numbers of rewards offered (i.e. Kraus et al. 2016; Zhou et al. 2018), and the use of prosocial cues in campaign messages (i.e. Calic and Mosakowski 2016; Pietraszkiewicz et al. 2017). In addition, research also found a positive association between campaign success and general perceptions of fundraiser preparedness (i.e. Kunz et al. 2017) and campaign quality (i.e. Hobbs et al. 2016). 
Second, in terms of crowd engagement, most research finds a positive association between campaign success and number of social media shares (i.e. Hobbs et al. 2016; Kromidha and Robson 2016), crowd comments and Q\&A messages (i.e. Lechtenbörger et al. 2015; Wessel et al. 2017), as well as third party endorsements (i.e. Calic and Mosakowski 2016; Guo et al. 2015). In addition, negative associations with campaign success were identified with respect to fake social media buzz (i.e. Wessel et al. 2016).

And third, in terms of campaign dynamics, most research finds a positive association between success and herding dynamics where early contributions by some is followed by later contributions by others (i.e. Borst et al. 2017; Gera and Kaur 2017), and the extent to which others have contributed earlier (i.e. Colombo et al. 2015; Skirnevskiy et al. 2017).

All these findings are based on indicators that were used for capturing relevant theoretical concepts explaining their role in influencing success. One such popular theory is Petty and Cacioppo's (1986) Elaboration Likelihood Model ('ELM'). Underlying this model is the argument that persuasion in communication can be achieved through cues processed in both central and peripheral routes. Central route to persuasion implies an extensive consideration of the message arguments that leads to attitude formation, change, or endurance that is more persistent and predictive. A peripheral route to persuasion implies little investment of cognitive efforts, and being relatively unaffected by argument quality, while relying on cues such as source credibility and pre-existing heuristics. Unsurprisingly, thanks to its parsimony, flexibility and relevance, the ELM was successfully used in several reward crowdfunding success studies (i.e. Bi et al. 2017; Guo et al. 2015; Li et al. 2017; Zheng et al. 2016), where various factors were considered as cues processed under each of these routes to persuasion.

However, while persuasion is one objective to be achieved on the way to campaign success, gaining the trust of prospective backers is another, either in enabling persuasion, or resulting from it.

\section{Trust}

Currall and Inkpen (2006) defined trust as the decision of one party to rely on another party under condition of risk. Such reliance is based on the expected trustworthiness of the other party, and the risk reflects the likelihood of negative outcomes to be experienced by the first party should the other party prove untrustworthy.

According to $\mathrm{Ba}$ (2001) trust in business relations develops from calculus-based trust to information-based trust, and eventually into transference-based trust. Calculus-based trust is an on-going economic calculation comparing the value created through sustaining a relationship to the costs of maintaining or severing it. Information-based trust is based on accumulated knowledge and experience, whereas relations develop, the parties gain more information about each other and create a degree of predictability about their likely actions under different conditions. Transference-based trust is indirectly transferred from a trusted partner to a less known one. Here, one party develops trust to a third party based on its existing trust to a second party that endorses the third party. Other typologies of trust include distinguishing between $\operatorname{cog}$ nitive trust, as depending on knowledge of- and experience with- the partner, and affective trust, as depending on care and concern for the partner (Johnson and Grayson 2005); or between calculus trust, as based on cost-benefit assessments, and relationship trust, as based on accumulated experiences with a party over time (Kang et al. 2016).

While most conceptualizations emerge from the individual level, they are applied and generalized across units of analysis so as to encompass trust at more complex social levels (i.e. groups, organizations, etc.), as they all make trust decisions with concrete and measurable outcomes that follow them (Currall and Inkpen 2006). In this context, interesting work by Delhey and Newton $(2003,2005)$ showed that societies differ in terms of their level of social trust, defined as "the belief that others will not deliberately or knowingly do us harm, if they can avoid it, and will look after our interests, if that is possible" (Delhey and Newton 2005, p. 311.). Their survey covered 60 countries, which were later divided into four sub-groups based on the percentage of respondents in each country indicating trust in others. These groups were labelled as either high-, medium-, low-, or no trust societies. Highest trust was recorded in Norway with 65\%, and lowest in Brazil with 3\%. However, such measurement was found lacking as it ignored the scope or 'radius' of people to which such trust was afforded. Accordingly, a follow up study, incorporated both dimensions of level of trust and radius of trust, with the latter also capturing the extent to which trust is afforded to the general public (e.g. generalized social trust) versus a limited number of in-group members (e.g. particularized social trust) (Delhey et al. 2011).

\section{Trust in crowdfunding}

Interest in the role of trust in online exchanges has been growing dramatically in the last two decades. Due to the spatial separation and information asymmetries underlying online exchanges, the gaining of trust in online marketplaces has been widely recognized as one of the prime objectives in e-commerce, e-marketing, and online community management (Ba 2001; Gefen et al. 2003; Kim and Peterson 2017). Specifically, in e-marketing, trust is signaled through the building of secure websites, provision of quality content, and management of social media reach and interactions (Brynjolfsson and Smith 2000). 
In the context of crowdfunding, earlier research showed that trust in the fundraiser was positively associated with funding intentions in reward crowdfunding in Taiwan (Liang et al. 2019) and Korea (Moon and Hwang 2018). A different study distinguishing between calculus trust (based on rational cost-benefit analysis) and relational trust (based on emotional bonds and social interaction) showed that both were positively associated with willingness to contribute financially to equity crowdfunding campaigns in China (Kang et al. 2016). Further arguing for the critical dimension of relational trust, Zhao and Ving (2019), showed that fundraisers' engagement in guanxiestablishing behavior (long term investments in relationships), and its intensity, were positively associated with performance of reward campaigns in China.

Interestingly, crowdfunding research employing trust theory has mostly emerged from East Asian cultural contexts with few exceptions. One was a study by Steigenberger (2017), who analyzed survey data from a majority of American and European supporters of game development reward crowdfunding campaigns. This study found no significant associations between competence- and integrity-trust perceptions and contribution amounts. Another was a study in Israel, showing that trust in creators was positively associated with creating a community around promoted concepts, but non-significant associations with campaign performance (Efrat et al. 2019). A different study in the Mexican context, showed that investments in relational trust were found to be rewarded with greater success of campaigns (Madrazo-Lemarroy et al. 2019).

Based on the importance of trust and the acknowledgement that proclivity towards trusting others differs across cultures (Delhey and Newton 2005; Delhey et al. 2011; Falk et al. 2018), we find merit in investigating possible effects of such differences on crowdfunding campaign design and success.

\section{Hypotheses}

To investigate the role of trust in campaign design and outcomes, we build on linking concepts from trust and persuasion theory. Specifically, we suggest that reward crowdfunding campaign design and outcomes are influenced by prevailing social proclivities towards trusting others in the market in which campaigns are launched.

Generally, earlier research shows that trust negatively influences perceived risk (Siegrist et al. 2005) and that members of the public tend to rely on social trust when making judgments of risks and benefits when personal knowledge about a hazard is lacking (Siegrist and Cvetkovich 2000). Since crowdfunding remains a relatively novel phenomenon in most markets (Ziegler et al. 2020), it incorporates a degree of risk (Shneor and Munim 2019), where prospective backers are relatively inexperienced (Davis et al. 2017), and the majority of them report one-time contributions (Kuppuswamy and Bayus 2018), one can safely assume that most contributors may rely on their social trust perceptions when considering contributions to crowdfunding campaigns.

For anchoring the discussion on the role of social trust in crowdfunding realities we highlight the need of fundraisers to gain the trust of a wide circle of prospective supporters in the social environments in which they operate. Building on the works presented earlier on social trust levels (Delhey and Newton 2005), and the radius of people to which it is afforded (Delhey et al. 2011), we distinguish between two types of societies. First, high trust societies (hereafter 'HTS') exhibiting either high or medium levels of social trust, and that such trust is afforded to a relatively wide circle of outgroup people (e.g. generalized social trust). And second, low trust societies (hereafter 'LTS') exhibiting low or no social trust levels, or those exhibiting high levels of social trust but only towards in-group versus out-group members (e.g. particularized social trust).

An important way to win the trust of others is through persuasion. In crowdfunding practice, to minimize prospective backers' risk perceptions about the crowdfunding campaign, fundraisers incorporate certain elements into their campaign development and execution processes. According to the ELM (Petty and Cacioppo 1986), such elements serve as cues processed under either a central or peripheral route to persuasion. As presented earlier, while the former involves careful rational consideration and substantial cognitive effort, the latter involves low cognitive efforts while relying on pre-existing heuristics.

Building on the above, we suggest that since fundraisers in LTS will face greater trust barriers than those in HTS, their prospective backers will engage in greater cognitive effort when processing campaign information and will require more cues for processing under a central route to persuasion than a peripheral one. Such requirements for more detailed information will serve as an information asymmetry reduction mechanism, resulting in lower perceived uncertainties and associated risks. On the other hand, backers in HTS, assuming greater trustworthiness of fundraisers, may be compelled to using less cognitive efforts when processing campaign information, requiring fundraisers to invest in supporting peripheral cues to persuasion to a greater extent than fundraisers in LTS. Such peripheral cues are meant to satisfy minimal and concise information needs for a more limited cognitive effort using pre-existing heuristics. In line with this logic, we hypothesize the following:

\section{H1: Reward crowdfunding campaigns from low trust so- cieties will exhibit higher levels of cues typical to a cen- tral route of persuasion than in high trust societies. \\ $\mathrm{H} 2$ : Reward crowdfunding campaigns from high trust societies will exhibit higher levels of cues typical to a peripheral route of persuasion than in low trust societies.}

Beyond the extent to which various campaign elements are made available it is also relevant to examine to what extent 
their availability affects successful outcomes of campaigns. Here, Zheng et al.'s (2016) study of Chinese reward crowdfunding suggested that 'trust management', reflecting certain actions taken by fundraisers, significantly promoted fundraising performance. Specifically, the study showed that this was achieved via both a central route, captured through indicators of entrepreneur's creditworthiness (historical success record and backing others' campaigns), and peripheral route, captured through an indicator of entrepreneur-sponsor interactions (Ibid.). Similarly, Bi et al.'s (2017) analysis revealed that central route information (signals of project quality) and peripheral route information (e-Word of Mouth) had almost equal effects on funder investment decisions in the Chinese reward crowdfunding context. However, other studies in China (Guo et al. 2015; Wang and Yang 2019) showed that while central route information was associated with amounts raised (including: detailed information, fundraising difficulty, product innovativeness, product quality, and creator ability), some peripheral information had similar effects (including: availability of video, availability of recommendations, and webpage visual design), while other peripheral information did not (including: number of lovers and followers, and platform reputation).

Other research using data from two US-based global reward crowdfunding platforms, showed that the peripheral cue of passion expressions in campaign video pitches was positively associated with funding amounts ( $\mathrm{Li}$ et al. 2017). Here, the study's authors argued that backers in this context have relatively low expertise and low-vested interest in the new ventures they consider supporting and are thus more likely to follow a peripheral route to persuasion and rely on simple cues in their decision making (Ibid.). The notion that inexperienced backers are more influenced by cues associated with a peripheral route of persuasion, was also shown in a later study of US-based campaigns on Kickstarter (Allison et al. 2017).

From a trust perspective, while China exhibits high levels of social trust, it is reserved to a narrow list of in-group members, and does not extend to out-group members in the general public (Delhey et al. 2011). In accordance with our definition above, it will fall under a definition of LTS, as fundraisers outside a prospective backer's in-group will face greater challenges in gaining the trust of an out-group member. On the other hand, the USA, exhibits medium levels of social trust overall but these are extended to a relatively large part of the public (Ibid.). In this case, according to our definition above, it falls under HTS, as fundraisers outside a prospective backer's in-group are likely to face similar moderate levels of challenge in winning the trust of both in-group and out-group members.

Accordingly, we suggest that prospective backers in LTS versus HTS will not only invest more cognitive efforts in processing campaign information, but will also be more likely to be persuaded towards financial contribution, when presented with more detailed and comprehensive central route cues by the fundraisers. On the other hand, backers in HTS versus LTS will rely on less cognitively demanding cues in a peripheral route of persuasion and will be more likely to be persuaded by the prevalence of such cues. Thus, we hypothesize the following:

\section{H3: Central route cues will be associated with campaign success in low trust societies but not in high trust societies. \\ H4: Peripheral route cues will be associated with success in high trust societies but not in low trust societies.}

Management of social media interactions is viewed as one of the most important trust signals used by e-marketers (Brynjolfsson and Smith 2000). Crowdfunding campaigning incorporates active sharing of news about the campaign and its progress via social media. Earlier research shows that sharing of news via social media is driven by self-perception of opinion leadership and status seeking, as well as by socializing motivations and relationship strengths (Lee and Ma 2012; Ma et al. 2014).

However, social media interactions between fundraisers and backers remains difficult to classify as information uniquely processed by either central or peripheral routes to persuasion. On the one hand, social media messages have been considered as peripheral information in some studies, mostly suggesting that either a fundraiser or their recommender's credibility is easily factored into decision making processes (Guo et al. 2015; Zheng et al. 2016). Others, however, claim that recommendations may not be easy to cognitively process, as they involve deeper considerations of shortand long-term relational outcomes, as well as felt respect, care, and loyalty to individuals with whom one engages. Indeed, some research shows that people are more likely to invest in carefully processing messages provided by those whose opinion they value. In this respect, some found that source expertise information was processed more as a central persuasion cue than as peripheral one (Homer and Kahle 1990). Furthermore, a recent study showed that expert celebrity endorsements in a crowdfunding campaign are processed through a central route (Lee and Koo 2016). Hence, social media messages can be processed via both central and peripheral routes to persuasion pending on the specific context and individuals involved.

Shared information via social media often comes in the form of Word-of-Mouth (Chu and Kim 2011), and while in crowdfunding it may be initiated or encouraged by campaign owners, it remains up to prospective backers to decide whether to share such information with their own network of contacts or not. Overall, research on online shopping shows that the perceived importance of Word-of-Mouth is equal to or even higher than that of self-evaluation in situations where product quality is unknown (Makoto et al. 2011). Reward 
crowdfunding represents a riskier form of shopping where products are pre-purchased before they are fully produced. Nevertheless, social media information sharing was found to be positively associated with reward crowdfunding campaign success in both what has been earlier defined as relatively high trust societies such as the USA (Byrnes et al. 2014; Wessel et al. 2017) and Germany (Lechtenbörger et al. 2015), and relatively low trust societies such as China (Bi et al. 2017; Liao et al. 2015) and Mexico (Madrazo-Lemarroy et al. 2019).

Here, while social media information sharing may be a cue primarily processed through a central route to persuasion in LTS, at the same time, it may also serve as a cue primarily processed through peripheral route to persuasion in HTS. Accordingly, we suggest that regardless of social trust levels in the target market, information conveyed in social media engagements will enhance campaign success whether being processed via central or peripheral routes to persuasion.

Hence, we hypothesize the following:

H5: Regardless of trust levels, extent of social media shares is positively associated with campaign success.

\section{Methods}

\section{Context}

For our study, we have chosen to collect data in two contexts representing two national markets with opposite positions along the social trust dimension, namely - Finland and Poland. The former represents a HTS with $49 \%$ indicating trusting others, while the latter a LTS with $18 \%$ indicating trusting others (Delhey and Newton 2005). Here, while these percentages have exhibited some changes through the years, the relative position of the two cultures has remained unchanged during the forty years in which the World Values Survey (WVS) data was collected (1981-2020) (Haerpfer et al. 2020). Most recently, the seventh wave of WVS data collection (2017-2020) showed that $68 \%$ of Finns indicated that most people can be trusted, while $24 \%$ of Poles indicated the same (Ibid.). Moreover, since both the respondents of the WVS (Delhey and Newton 2005) and the crowdfunding funders in our respective geographies were mostly high and middle income individuals (Ziegler et al. 2020), there is a good fit between the samples used to assess social trust and the profiles of those who have been doing most of the funding in the same period.

Furthermore, focusing on Finland and Poland allows us to answer earlier calls to better capture the majority of actors in national crowdfunding markets, which have been underrepresented in existing crowdfunding success literature often dominated by the unique and large economies of the USA and China (Shneor and Vik 2020).
At the time of data collection, in Finland, there were 23 active platforms offering crowdfunding services under different models, five of which offering reward crowdfunding. According to Ziegler et al. (2020) Finland represented the 7th largest European market, with a total volume of USD 379 million raised in 2018, growing 71\% from USD 222 million in 2017. More specifically, between 2016 and 2018, a total of USD 5.6 million have been raised through reward crowdfunding campaigns in Finland (Ziegler et al. 2019; Ziegler et al. 2020).

In Poland, there were 24 active platforms offering crowdfunding services under different models, five of which offering reward crowdfunding. According to Ziegler et al. (2020) Poland represented the 8th largest European market, with a total volume of USD 333 million raised in 2018, growing 107\% from USD 160 million in 2017. More specifically, between 2016 and 2018, a total of USD 23.9 million have been raised through reward crowdfunding campaigns in Poland (Ziegler et al. 2019, Ziegler et al. 2020).

Both platforms cater primarily to their country fellowmen and to a lesser extent to its diaspora in other European countries. The absolute majority of campaigns on both platforms are presented in the national languages (i.e. Polish and Finnish). In the few cases where campaigns are provided in English, they are often prepared by immigrants still seeking support from local prospective backers.

\section{Data sources and collection procedure}

Our unit of analysis is the crowdfunding campaign. Data about campaigns were manually collected from the leading national reward crowdfunding platforms in both Finland and Poland - Mesenaatti.me and PolakPotrafi.pl, respectively. Such data was further supplemented by figures about social media shares collected for each campaign from a separate website offering online web engagement statistics SharedCount.com.

The Finnish data included 700 randomly selected campaigns from the Mesenaatti.me platform covering campaigns launched between the platforms starting date in January 2013 and April 2018. During this period, over 800 campaigns were launched and nearly EUR 3 million (approx. USD 3.3 million) were raised on the platform.

Accordingly, the Polish data included 700 randomly selected campaigns from the PolakPotrafi.pl platform covering campaigns launched between the platform starting date in March 2011 and April 2018. During this period, over 4000 campaigns were launched and nearly PLN 25 million (approx. USD 7 million) were raised on the platform. To ensure comparability of results financial data from PolakPotrafi.pl were converted into EUR based on average monthly exchange rates as published by the central bank of Poland. 


\section{Measurements}

In line with common practice in earlier research, we have used two measures of campaign success for capturing our dependent variable of campaign success (Kaartemo 2017; Shneor and Vik 2020). The first, a dichotomous variable capturing success in the sense of whether the campaign raised its minimum target sum goal (assigned the value 1) or not (assigned the value 0 ). The second, a continuous variable capturing relative success in terms of the ratio between the sum amount raised and the minimum target sum goal set for the campaign.

In line with earlier research, we have used various campaign elements to capture our independent variables. First, for capturing social media engagements we have used the $\log +1$ value of number of Facebook shares of the campaign's URL address. This data was collected from the SharedCount. com website. Here, earlier research showed that number of Facebook shares was positively associated with campaign success in other contexts (i.e. Lechtenbörger et al. 2015; Wessel et al. 2017).

Second, for capturing information elements requiring higher levels of cognitive efforts (central cues), we have used the $\log +1$ value of the number of words used in the campaign text, the $\log$ value of the number of rewards offered representing more options for consideration, the log average price of all rewards offered and the log average price of the cheapest three rewards offered both for assessment of price fairness and affordability. Such variables require efforts in terms of amount of information to be processed or by requiring basic mathematical calculations by the backer. Earlier research confirmed a positive association of campaign success and the length of text (i.e. Koch and Siering 2019; Kunz et al. 2017; Li and Martin 2016), as well as the number of rewards offered (i.e. Calic and Mosakowski 2016; Zhou et al. 2018).

Third, for capturing information elements requiring lower levels of cognitive efforts (peripheral cues), we have used the $\log +1$ value of the number of images used in the campaign, the $\log$ value of the number of days the campaign has been running, the $\log +1$ value of the minimum goal sum set for the campaign as a quick indicator of feasibility, and the number of years since platform establishment at time of campaign (assuming platform credibility increases with period of time in which it has existed). Earlier research confirmed a positive association of success and number of images (i.e. Kim et al. 2016; Zhou et al. 2018), number of campaign days (i.e. Kromidha and Robson 2016; Zheng et al. 2016), and a negative association with goal sum (i.e. Koch and Siering 2019; Zhou et al. 2018).

\section{Analyses and results}

Table 1 presents the descriptive statistics of the variables studied in both samples, as well as tests the significance of differences in means. Overall, since equality of variance was disconfirmed for all variables with exception of goal sum, test of significance of mean differences followed the assumption of unequal variances. Elements associated with central cues to persuasion exhibited significantly higher levels in Poland than in Finland with respect to word count $(\mathrm{t}(1194.074)=-28.743$, $p=.001)$, reward count $(\mathrm{t}(1311.466)=-27.252, \mathrm{p}=.001)$, and average price of cheapest rewards $(\mathrm{t}(818.315)=$ $-11.726, p=.001)$. Hence, largely supporting H1. An exception here, is higher levels of average reward price in Finland $(\mathrm{t}(1367.83)=14.381, \mathrm{p}=.001)$, which may be explained by higher purchasing power in Finland rather than higher trust.

Some elements associated with peripheral cues to persuasion exhibited significantly higher levels in Finland than in Poland including the campaign duration $(\mathrm{t}(1193.357)=7.624, \mathrm{p}=.001)$ and goal sum $(t(1398)=6.101, p=.001)$. Other elements exhibited higher levels in Poland than in Finland. These included higher platform age at campaign launch $(\mathrm{t}(1343.481)=$ $-23.064, p=.001$ ), which is explained by the fact the Polish platform was established 2 years earlier than the Finnish platform rather than by differences associated with social trust. Moreover, the same result was achieved with respect to number of images $(\mathrm{t}(925.743)=-99.815, \mathrm{p}=.001)$, which may suggest that while images in general may reduce cognitive effort, having many of them may still increase it. Accordingly, we conclude that our findings partially support $\mathrm{H} 2$.

Next, we proceed with regression analyses. Tables 2 and 3 present the inter-correlations between model variables in each study context. These indicate that none of the variables are excessively correlated with each other and are well within the acceptable level of 0.7 or lower. In addition, a variance inflation factor (VIF) analyses were conducted and reported in Tables 4 and 5, showing maximum VIF value of 2.097, which is well below the strictest threshold value of 4 (Hair et al. 2010). Taken together, these findings indicate that there is no problem of multicollinearity in the data.

We estimate two models in each context. Model 1 uses the extent of success as the dependent variable and estimated using a linear regression. Model 2 uses the dichotomous indicator of success and estimated using a logistic regression. The analyses are presented in Tables 3 and 4 while indicating that both models are significant in both contexts. Model 1 explains $37 \%$ of the variance in the Finnish data and $24 \%$ in the Polish data. Model 2 explains 33\% in the Finnish data and $18 \%$ in the Polish data.

First, in terms of central cues, the number of words is significantly associated with both success and extent of success in Poland, but not in Finland. The number of rewards offered and the average price of the cheapest three rewards were associated with success in Poland but not in Finland, but significantly associated with extent of success in both contexts albeit still with higher levels of significance in Poland. This suggests that for achieving success beyond minimum goal in 
Table 1 Descriptive Statistics, Equality of Variance, and Equality of Means Tests

\begin{tabular}{|c|c|c|c|c|c|c|c|c|c|}
\hline \multirow[t]{2}{*}{ Variable } & \multirow[t]{2}{*}{ platform } & \multirow[t]{2}{*}{ Mean } & \multirow[t]{2}{*}{ Std. Deviation } & \multicolumn{2}{|c|}{$\begin{array}{l}\text { Levene's Test for } \\
\text { Equality of Var }\end{array}$} & \multicolumn{4}{|c|}{ t-test for Equality of Means } \\
\hline & & & & $\mathrm{F}$ & Sig. & Equal Variances & $\mathrm{t}$ & df & Sig. (2-tail) \\
\hline \multirow[t]{2}{*}{ Platform_Age } & Mesenaatti & 2.9271 & 1.21465 & 66.035 & 0.001 & assumed & -23.064 & 1398 & 0.001 \\
\hline & Polakpotrafi & 4.6029 & 1.48988 & & & not assumed & -23.064 & 1343.481 & 0.001 \\
\hline \multirow[t]{2}{*}{ log_facebook_shares } & Mesenaatti & 1.5791 & 0.5946 & 78.659 & 0.001 & assumed & 7.013 & 1398 & 0.001 \\
\hline & Polakpotrafi & 1.3239 & 0.75705 & & & not assumed & 7.013 & 1323.677 & 0.001 \\
\hline \multirow[t]{2}{*}{ log_duration } & Mesenaatti & 1.6589 & 0.26393 & 106.808 & 0.001 & assumed & 7.624 & 1398 & 0.001 \\
\hline & Polakpotrafi & 1.5685 & 0.16988 & & & not assumed & 7.624 & 1193.357 & 0.001 \\
\hline \multirow[t]{2}{*}{ log_goal } & Mesenaatti & 3.3685 & 0.4196 & 0.13 & 0.718 & assumed & 6.101 & 1398 & 0.001 \\
\hline & Polakpotrafi & 3.2282 & 0.44095 & & & not assumed & 6.101 & 1394.571 & 0.001 \\
\hline \multirow[t]{2}{*}{ log_image_count } & Mesenaatti & 0.296 & 0.32601 & 511.619 & 0.001 & assumed & -99.815 & 1398 & 0.001 \\
\hline & Polakpotrafi & 1.6245 & 0.13311 & & & not assumed & -99.815 & 925.743 & 0.001 \\
\hline \multirow[t]{2}{*}{ log_campaign_body_wordcount } & Mesenaatti & 2.4375 & 0.35467 & 51.86 & 0.001 & assumed & -28.743 & 1398 & 0.001 \\
\hline & Polakpotrafi & 2.8958 & 0.22853 & & & not assumed & -28.743 & 1194.074 & 0.001 \\
\hline \multirow[t]{2}{*}{ log_rewards_count } & Mesenaatti & 0.8394 & 0.25727 & 26.054 & 0.001 & assumed & -27.252 & 1398 & 0.001 \\
\hline & Polakpotrafi & 1.1737 & 0.19782 & & & not assumed & -27.252 & 1311.446 & 0.001 \\
\hline \multirow[t]{2}{*}{ log_rewards_avg_amount } & Mesenaatti & 2.1799 & 0.53574 & 7.081 & 0.008 & assumed & 14.381 & 1398 & 0.001 \\
\hline & Polakpotrafi & 1.7957 & 0.46129 & & & not assumed & 14.381 & 1367.83 & 0.001 \\
\hline \multirow[t]{2}{*}{ log_rewards_avg_amount_cheapest3 } & Mesenaatti & 0.3878 & 0.05894 & 393.905 & 0.001 & assumed & -11.726 & 1398 & 0.001 \\
\hline & Polakpotrafi & 0.4806 & 0.20101 & & & not assumed & -11.726 & 818.315 & 0.001 \\
\hline \multirow[t]{2}{*}{ Extent of Success (log_achievement) } & Mesenaatti & 0.282 & 0.23108 & 44.26 & 0.001 & assumed & 5.526 & 1398 & 0.001 \\
\hline & Polakpotrafi & 0.2226 & 0.16622 & & & not assumed & 5.526 & 1269.6 & 0.001 \\
\hline \multirow{2}{*}{$\begin{array}{l}\text { Success } \\
\text { (reached goal or not) }\end{array}$} & Mesenaatti & 0.6 & 0.491 & 11.643 & 0.001 & assumed & 1.784 & 1398 & 0.075 \\
\hline & Polakpotrafi & 0.55 & 0.498 & & & not assumed & 1.784 & 1397.718 & 0.075 \\
\hline
\end{tabular}

Notes: Finland $N=700$, Poland $\mathrm{N}=700$

a HTS, central cues to persuasion are also factored in. Accordingly, our findings support H3 for success, but not for extent of success.

Second, in terms of peripheral cues, both the campaign goal sum and the number of images used in the campaign were significantly associated with success and extent of success in both contexts. Platform age was significantly associated with success in Finland but not Poland, but it was significantly associated with extent of success in Poland but not in Finland. Hence, overall, we do not find support for H4 in our data.

And third, the findings show that social media shares are positively and significantly associated with both campaign

Table 2 Correlation Matrix - Finland

\begin{tabular}{|c|c|c|c|c|c|c|c|c|c|}
\hline & & 1 & 2 & 3 & 4 & 5 & 6 & 7 & 8 \\
\hline 1 & Platform_Age & 1 & & & & & & & \\
\hline 2 & log_facebook_shares & -0.052 & 1 & & & & & & \\
\hline 3 & log_duration & $-0.074 *$ & 0.042 & 1 & & & & & \\
\hline 4 & log_goal & 0.050 & $0.215 * * *$ & $0.263 * * *$ & 1 & & & & \\
\hline 5 & log_image_count & $0.171 * * *$ & $0.119 * * *$ & -0.026 & $0.147 * * *$ & 1 & & & \\
\hline 6 & log_campaign_body_wordcount & 0.018 & $0.236 * * *$ & 0.061 & $0.186^{* * *}$ & $0.232 * * *$ & 1 & & \\
\hline 7 & log_rewards_count & $0.130 * * *$ & $0.200 * * *$ & -0.029 & $0.118 * * *$ & $0.22 * * *$ & $0.273 * * *$ & 1 & \\
\hline 8 & log_rewards_avg_amount & $0.071 *$ & $0.101 * *$ & $0.163 * * *$ & $0.41 * * *$ & $0.125 * * *$ & $0.182 * * *$ & $0.403 * * *$ & 1 \\
\hline 9 & 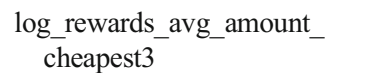 & 0.051 & $-0.125^{* * *}$ & $0.099 * *$ & $0.209 * * *$ & 0.006 & $-0.063 * *$ & $-0.376^{* * *}$ & $0.359 * * *$ \\
\hline
\end{tabular}

Notes: $\mathrm{N}=700$, Significance: $* P \leq 0.05, * * P \leq 0.01, * * * P \leq 0.001$ 
Table 3 Correlation Matrix - Poland

\begin{tabular}{|c|c|c|c|c|c|c|c|c|c|}
\hline & & 1 & 2 & 3 & 4 & 5 & 6 & 7 & 8 \\
\hline 1 & Platform_Age & 1 & & & & & & & \\
\hline 2 & log_facebook_shares & $0.374 * * *$ & 1 & & & & & & \\
\hline 3 & log_duration & 0.020 & $-0.094 * *$ & 1 & & & & & \\
\hline 4 & log_goal & $0.245 * * *$ & $0.212 * * *$ & $0.273 * * *$ & 1 & & & & \\
\hline 5 & log_image_count & $0.071 *$ & 0.044 & $0.070 *$ & $0.330 * * *$ & 1 & & & \\
\hline 6 & log_campaign_body_wordcount & $0.069 *$ & 0.053 & 0.025 & $0.267 * * *$ & $0.441 * * *$ & 1 & & \\
\hline 7 & log_rewards_count & 0.046 & $0.147 * * *$ & $0.068^{*}$ & $0.338 * * *$ & $0.453 * * *$ & $0.285 * * *$ & 1 & \\
\hline 8 & log_rewards_avg_amount & $0.068^{*}$ & $0.136^{* * * *}$ & $0.125 * * *$ & $0.583 * * *$ & $0.222 * * *$ & $0.150 * * *$ & $0.378 * * *$ & 1 \\
\hline 9 & $\begin{array}{l}\text { log_rewards_avg_amount_ } \\
\text { cheapest3 }\end{array}$ & $0.075^{*}$ & $0.085^{*}$ & -0.054 & 0.057 & $-0.133 * * *$ & $-0.088 * *$ & $-0.303 * * *$ & 0.036 \\
\hline
\end{tabular}

Notes: $\mathrm{N}=700$, Significance: $* \mathrm{P} \leq 0.05, * * \mathrm{P} \leq 0.01$, *** $\mathrm{P} \leq 0.001$

success and extent of success at the 0.001 level in both contexts, hence supporting $\mathrm{H} 5$.

Finally, two indicators were not significantly associated with success in either Finland or Poland. The central cue of average price of rewards offered, which when taken together with findings about average price of cheapest rewards, indicates that most backers consider pricing only with respect to cheap rather than the averagely priced rewards. And the peripheral cue of campaign duration, which may indicate that backers may not be concerned with campaign duration per se, but with implications of it. This was shown in earlier research in terms of how much funds were raised from others within the set time frame (Colombo et al. 2015; Oh and Baek 2016), or number of days left to campaign end (Mendes-Da-Silva et al. 2015).

\section{Discussion}

The study presents findings suggesting that reward crowdfunding practice may be influenced by proclivities towards social trust in the societies in which it is practiced. As

Table 4 Regression Models - Finland

\begin{tabular}{|c|c|c|c|c|}
\hline Variables & Model 1Extent of Success & & Model 2 Success & VIF \\
\hline Platform_Age & $\begin{array}{l}0.053 \\
(0.006)\end{array}$ & & $\begin{array}{l}0.190 * \\
(0.084)\end{array}$ & 1.068 \\
\hline log_facebook_shares & $\begin{array}{l}0.555 * * * \\
(0.012)\end{array}$ & & $\begin{array}{l}3.006 \text { *** } \\
(0.260)\end{array}$ & 1.139 \\
\hline log_duration & $\begin{array}{l}-0.009 \\
(0.027)\end{array}$ & & $\begin{array}{l}-0.351 \\
(0.371)\end{array}$ & 1.100 \\
\hline log_goal & $\begin{array}{l}-0.390 * * * \\
(0.019)\end{array}$ & & $\begin{array}{l}-2.485 * * * \\
(0.307)\end{array}$ & 1.351 \\
\hline log_image_count & $\begin{array}{l}0.086^{* *} \\
(0.023)\end{array}$ & & $\begin{array}{l}0.738^{*} \\
(0.326)\end{array}$ & 1.135 \\
\hline log_campaign_body_wordcount & $\begin{array}{l}0.014 \\
(0.021)\end{array}$ & & $\begin{array}{l}-0.400 \\
(0.300)\end{array}$ & 1.174 \\
\hline log_rewards_count & $\begin{array}{l}0.099 * \\
(0.039)\end{array}$ & & $\begin{array}{l}0.935 \\
(0.563)\end{array}$ & 2.088 \\
\hline log_rewards_avg_amount & $\begin{array}{l}0.021 \\
(0.19)\end{array}$ & & $\begin{array}{l}0.182 \\
(0.259)\end{array}$ & 2.097 \\
\hline log_rewards_avg_amount_cheapest3 & $\begin{array}{l}0.090^{*} \\
(0.161)\end{array}$ & & $\begin{array}{l}2.411 \\
(2.235)\end{array}$ & 1.885 \\
\hline \multicolumn{5}{|l|}{ Model fit } \\
\hline Model F $(9,690)$ & $47.398 * * *$ & $\begin{array}{l}\text { Model } X^{2} \\
\text { Log likelihood }\end{array}$ & $\begin{array}{l}281.679 * * * \\
662.136\end{array}$ & \\
\hline Adjusted $R^{2} / R^{2}$ & $0.374 / 0.382$ & Pseudo $R^{2}$ & 0.331 & \\
\hline $\mathrm{N}$ & 700 & $\mathrm{~N}$ & 700 & \\
\hline
\end{tabular}

Notes: Model 1 reports a linear regression. Model 2 reports a logistic regression. Standard errors in brackets. Significance noted as: $* \mathrm{P} \leq 0.05, * * \mathrm{P} \leq$ $0.01, * * * \mathrm{P} \leq 0.001$ 
Table 5 Regression Models Poland

\begin{tabular}{|c|c|c|c|c|}
\hline Variables & $\begin{array}{l}\text { Model } 1 \\
\text { Extent of Success }\end{array}$ & & $\begin{array}{l}\text { Model } 2 \\
\text { Success }\end{array}$ & VIF \\
\hline Platform_Age & $\begin{array}{l}-0.074 * \\
(0.004)\end{array}$ & & $\begin{array}{l}-0.109 \\
(0.063)\end{array}$ & 1.222 \\
\hline log_facebook_shares & $\begin{array}{l}0.180 * * * \\
(0.008)\end{array}$ & & $\begin{array}{l}0.603 * * * \\
(0.126)\end{array}$ & 1.241 \\
\hline log_duration & $\begin{array}{l}-0.007 \\
(0.034)\end{array}$ & & $\begin{array}{l}-0.895 \\
(0.534)\end{array}$ & 1.120 \\
\hline log_goal & $\begin{array}{l}-0.500 * * * \\
(0.017)\end{array}$ & & $\begin{array}{l}-2.099 * * * \\
(0.289)\end{array}$ & 1.923 \\
\hline log_image_count & $\begin{array}{l}0.195 * * * \\
(0.051)\end{array}$ & & $\begin{array}{l}2.240 * * \\
(0.810)\end{array}$ & 1.495 \\
\hline $\begin{array}{l}\text { log_campaign_body_ } \\
\text { wordcount }\end{array}$ & $\begin{array}{l}0.148 * * * \\
(0.027)\end{array}$ & & $\begin{array}{l}1.085 * \\
(0.431)\end{array}$ & 1.282 \\
\hline log_rewards_count & $\begin{array}{l}0.170 * * * \\
(0.035)\end{array}$ & & $\begin{array}{l}2.297 * * * \\
(0.586)\end{array}$ & 1.604 \\
\hline log_rewards_avg_amount & $\begin{array}{l}0.064 \\
(0.015)\end{array}$ & & $\begin{array}{l}0.090 \\
(0.239)\end{array}$ & 1.641 \\
\hline $\begin{array}{l}\text { log_rewards_avg_amount_ } \\
\text { cheapest3 }\end{array}$ & $\begin{array}{l}0.154 * * * \\
(0.030)\end{array}$ & & $\begin{array}{l}1.517 * * \\
(0.505)\end{array}$ & 1.169 \\
\hline \multicolumn{5}{|l|}{ Model fit } \\
\hline Model F $(9,690)$ & $24.722 * * *$ & $\begin{array}{l}\text { Model } X^{2} \\
\text { Log likelihood }\end{array}$ & $\begin{array}{l}136.490 * * * \\
826.904\end{array}$ & \\
\hline Adjusted $R^{2} / R^{2}$ & $0.234 / 0.244$ & Pseudo $R^{2}$ & 0.177 & \\
\hline $\mathrm{N}$ & 700 & $\mathrm{~N}$ & 700 & \\
\hline
\end{tabular}

Notes: Model 1 reports a linear regression. Model 2 reports a logistic regression. Standard errors in brackets. Significance noted as: $* \mathrm{P} \leq 0.05, * * \mathrm{P} \leq 0.01$, *** $\mathrm{P} \leq 0.001$ such, we both support and begin to untangle earlier macrolevel indications about such relations by presenting their implications at the micro level. Here, earlier macro-level analyses showed that social trust was positively associated with per capita crowdfunding volumes (Ziegler et al. 2019; Ziegler et al. 2020), while supporting a proposition earlier outlined by Kshetri (2015). The current study shows how such conditions manifest at the micro-level in campaign design and success dynamics.

Answering our first research question, we present that campaign elements that require greater cognitive effort are more prevalent in Poland (LTS) than in Finland (HTS). This supports the notion that backers in LTS will require more detailed information as part of their information asymmetry reduction efforts towards overcoming their general lower proclivity to trust others, than backers in HTS. Accordingly, fundraisers in LTS will have to provide longer and more detailed texts about the project, offer a wider variety of rewards, and price cheapest rewards slightly higher as they may be perceived as lower risk contribution options. Moreover, in terms of peripheral cues, HTS may be more accommodating to higher campaign goal sums and longer campaign durations, both of which may signal greater uncertainties that will be less welcomed in LTS.
Our study contributes insights to several current research streams. First, it contributes to the limited cross-cultural research in crowdfunding. Specifically, our study is one of the first to examine the differences between campaign features in societies based on their different proclivities towards social trust. Earlier cross-cultural research examined other cultural dimensions along which societies differ. Here, Cho and Kim (2017) conducted a content analysis of crowdfunding platforms in Korea and the US while coding campaign elements along some of Hofstede's (2001) cultural dimensions. They showed that Korean platforms exhibited features associated with collectivism to a greater degree than in the US, while US-based platforms exhibited features associated with power distance and uncertainty avoidance to a greater degree than in Korea. In this respect, our study supplements earlier work by suggesting an additional dimension along which culture may influence crowdfunding practice, namely - social trust.

Second, our study contributes to research on the role of social trust in crowdfunding practice. Earlier research has addressed differences in self-reported trust evaluations and their roles in predicting contribution intentions (Kang et al. 2016; Liang et al. 2019; Moon and Hwang 2018). In our study, we identify differences in crowdfunding campaign design and success dynamics that emerge in societies with different social 
trust proclivities. Such view presents two new insights. First, we show that trust is associated with campaign design and success dynamics, in addition to individuals' contribution intentions. And second, the extent to which different campaign elements contribute to gaining prospective backers' trust, depends not only on individual evaluations, but also on their fit with pre-existing social trust proclivities in the environments in which the campaigns are launched.

Third, our study also contributes to research on persuasion in crowdfunding which often uses the ELM framework as its theoretical anchor. Here, while earlier studies have shown significant associations between success and availability of campaign elements that were classified as either processed through central or peripheral routes (Bi et al. 2017; Guo et al. 2015; Li et al. 2017; Zheng et al. 2016), they have not examined the extent to which these are available in social environments characterized by different levels of social trust. And furthermore, earlier research also did not consider social trust as the mechanism that may explain differences in the extent to which availability of campaign elements was associated with successful campaign outcomes in different environments. Our study provides both.

Specifically, when answering our second research question about the impact of various campaign elements in different social trust contexts, we find that while central cues are associated with success to a greater extent in LTS than in HTS, differences in social trust do not seem to impact the way in which peripheral cues influence campaign success. Here, since earlier research on crowdfunding success has mostly drawn on samples from high and medium social trust environments (as classified in Delhey and Newton 2005), it is difficult to compare our results to earlier ones without comparative evidence from LTS with few exceptions.

One exception is the support to our findings with respect to the central cue of number of words in campaign text, which was found to be positively associated with both success and extent of success in a study of data from the LTS contexts of Indonesia (Aprilia and Wibowo 2017) and Mexico (MadrazoLemarroy et al. 2019). Other studies conducted in the medium social-trust environment of the US present both positive (Kunz et al. 2017; Zhou et al. 2018) and non-significant associations (Parhankangas and Renko 2017; Pietraszkiewicz et al. 2017). Overall, when combined together with our findings, we see that indeed the lower the social trust, the more influential does the length of campaign text become, from high impact in Indonesia, Mexico, and Poland (LTS), to mixed evidence in the US (medium social trust), and no effect in Finland (HTS).

Another exception, while contrary to our hypothesis, is the evidence that campaign duration does not affect success regardless of social trust levels. Here, studies conducted in the US, showed negative (Skirnevskiy et al. 2017), positive (Wessel et al. 2017), and non-significant (Hobbs et al. 2016) effects. Similarly, in LTS contexts, research shows both negative effect in Indonesia (Aprilia and Wibowo 2017) and Mexico (Madrazo-Lemarroy et al. 2019) and positive effects in Brazil (Mendes-Da-Silva et al. 2015). These findings indicate that backers may not be concerned with campaign duration per se, but with implications of it. In this respect, earlier research does show that how much funds were raised from others within the set time frame (Colombo et al. 2015; Oh and Baek 2016), or the number of days left to campaign end (Mendes-Da-Silva et al. 2015) were significantly associated with campaign success.

Finally, we find support to the suggestion that social media shares impact success regardless of social trust proclivities in the market, being important regardless of whether they are processed as either central or peripheral cues. Such finding is supported by earlier results of a study comparing campaign dynamics in China and the US (Zheng et al. 2014), showing that social capital dimensions (social network ties, obligation to fund others, and shared meaning) were significantly associated with campaign performance in both contexts. Furthermore, other studies, while not comparative in nature, also found consistent evidence for positive associations between success and social media shares and engagement in a variety of social trust contexts including China (Liao et al. 2015), Germany (Clauss et al. 2019), Korea (Oh and Baek 2016), Mexico (Madrazo-Lemarroy et al. 2019), and the US (Kunz et al. 2017; Wessel et al. 2017).

\section{Conclusions}

The importance of backer trust in enhancing the likelihood of positive crowdfunding campaign outcomes is well established (Chen et al. 2014; Kang et al. 2016; Liang et al. 2019; Madrazo-Lemarroy et al. 2019; Zhao and Vinig 2019). However, earlier research did not account for the contextual conditions that may influence the efforts needed to win such trust. Such concerns are especially relevant as research documents that different cultures exhibit different levels of proclivities towards trusting others (Delhey and Newton 2005; Delhey et al. 2011).

Accordingly, in the current study we investigate which reward crowdfunding campaign elements are more prevalent in high vs. low trust societies, and how do these elements affect the success of reward crowdfunding campaigns in high vs. low trust societies. We do so by analyzing data collected from randomly selected campaigns on two national reward crowdfunding platforms operating in differing social trust contexts, including 700 campaigns from Finland, representing a HTS, and 700 campaigns from Poland, representing a LTS.

Our analyses present several interesting findings. First, while campaigning in HTS may require less effort in developing elements that serve as cues in a central route to backer 
persuasion, such investments are necessary in LTS, where such cues are important for information asymmetry reduction. However, when fundraisers from HTS wish to achieve success beyond meeting minimum goals, they should invest in such cues as well. Second, we show that regardless of the levels of social trust in a society, social media engagements and sharing of information are critical for reward crowdfunding success. And third, we also find that while some elements representing cues for a peripheral route to persuasion are more prevalent in HTS than in LTS, they are associated with campaign success in both types of environments.

The main contribution of our study is in highlighting the importance of the exiting social trust conditions in influencing crowdfunding practice. Here, the extent of incorporating different campaign elements, as well as their association with successful outcomes, may both differ by the levels of social trust prevailing in the context in which the campaigns are launched. In this sense, we extended earlier insights on how trust is enhanced through proper campaign design, by acknowledging that campaign efforts originate from different departure points in terms of pre-existing levels of social trust proclivities in different cultures. Accordingly, campaign design should accommodate trust conditions under which a campaign is launched and tweak their intensity levels based on these conditions for ensuring successful outcomes. Furthermore, our study also contributes by studying trust in European crowdfunding contexts, complementing earlier research that was mostly conducted in East Asian contexts. Moreover, we also contribute to better understanding of crowdfunding dynamics on national platforms, as they represent the majority of crowdfunding platforms in operation (Ziegler et al. 2020), while earlier research was dominated by large global platforms.

\section{Limitations and implications for research}

While our study presents interesting insights, it does incorporate several shortcomings that should be acknowledged and serve as fruitful grounds for future research. First, the generalizability of our findings may be constrained to the specific countries, platforms, and period in which data was collected. Nevertheless, our study answers earlier calls to study crowdfunding in national crowdfunding platforms, as data from outlier global platforms (i.e. Kickstarter and Indiegogo) have been thoroughly investigated in multiple studies (Shneor and Vik 2020). Accordingly, we present findings from the contexts of national reward crowdfunding platforms in Finland and Poland. Nevertheless, researchers are encouraged to examine similar dynamics in other contexts, especially as driven by their differing social trust proclivities (Delhey et al. 2011; Falk et al. 2018), while both re-examining our findings and expanding on them.
Another fruitful way to explore the boundaries of the generalizability of our findings is in replication studies in different crowdfunding models, both in same national contexts, as well as in others. Specifically, researchers are encouraged to examine whether social trust proclivities will play a greater or lesser role in investment oriented crowdfunding practices (i.e. lending and equity crowdfunding) versus non-investment models (rewards and donations). Such call is in line with earlier suggestions for more research comparing models (Hoegen et al. 2017).

Furthermore, our findings are limited to the campaign elements we have recorded in our data. Future research may expand this list to incorporate additional campaign features that may serve as either central or peripheral cues. For example, central cues may include indicators of video pitch length, the inclusion of detailed financial information and plans, as well as information comparing own offerings to competing ones. Peripheral cues may include emotional appeals vs. rational ones, visual esthetics evaluations, indication of a single campaigner vs. a team, and demographic information about the lead fundraiser.

Finally, while social trust proclivities may serve as a compelling basis for explaining differences identified between the two contexts studied, other factors may still play a role in shaping them. Future research should explore alternative explanations for the identified differences. Such efforts may follow qualitative analyses aiming to flesh-out such explanations from interviews of relevant stakeholders, or quantitative analyses comparing the relative weight carried by social trust scores versus other macro-level variables in a larger scale study including multiple countries. Here, alternative aspects may include alternative dimensions of market e-readiness such as technological, legal, and financial and commercial infrastructures (Javalgi and Ramsey 2001), as well as alternative cultural dimensions such as collectivism/individualism and uncertainty avoidance (Lim et al. 2004).

\section{Implications for practice}

Our findings suggest implications for both campaign design by prospective fundraisers, as well as interface and service design by platforms. First, fundraisers that aim to attract backers from LTS should invest in trust enhancement through the provisioning of detailed information, a wider set of rewards, and by setting a slightly higher average price for cheapest rewards. Second, regardless of social trust context, fundraisers should invest in social media engagements and encourage the sharing of campaign information through social networks. Such efforts contribute to developing relational trust, and the information shared can be processed as either central or peripheral cues pending on context of interaction. Third, ambitious fundraisers from HTS that wish to try raising more than their minimum goal, should also invest in more 
central cues such as a larger number of rewards offered, and charging slightly higher prices for cheapest reward options.

Similar insights can feed into platform interface and service design. Platforms operating in LTS should require greater informational disclosure and may create detailed templates for would-be fundraisers to fill. Moreover, platforms in all contexts should invest in integrating social media engagement functionalities into campaign design templates, offer additional value added services in social media promotional support, or build automatic reminders into the system probing fundraisers to engage in social media throughout the campaign process, or based on accumulated results. Finally, platforms operating in HTS, may provide different campaign templates to different fundraisers based on their indicated levels of ambition at campaign registration.

Funding Open access funding provided by University of Agder.

Open Access This article is licensed under a Creative Commons Attribution 4.0 International License, which permits use, sharing, adaptation, distribution and reproduction in any medium or format, as long as you give appropriate credit to the original author(s) and the source, provide a link to the Creative Commons licence, and indicate if changes were made. The images or other third party material in this article are included in the article's Creative Commons licence, unless indicated otherwise in a credit line to the material. If material is not included in the article's Creative Commons licence and your intended use is not permitted by statutory regulation or exceeds the permitted use, you will need to obtain permission directly from the copyright holder. To view a copy of this licence, visit http://creativecommons.org/licenses/by/4.0/.

\section{References}

Allison, T. H., Davis, B. C., Webb, J. W., \& Short, J. C. (2017). Persuasion in crowdfunding: An elaboration likelihood model of crowdfunding performance. Journal of Business Venturing, 32(6), 707-725. https://doi.org/10.1016/j.jbusvent.2017.09.002

Alt, R., Beck, R., \& Smits, M. T. (2018). FinTech and the transformation of the financial industry. Electronic Markets, 28(3), 235243. https://doi.org/10.1007/s12525-018-0310-9

Appio, F. P., Leone, D., Platania, F., \& Schiavone, F. (2020). Why are rewards not delivered on time in rewards-based crowdfunding campaigns? An empirical exploration. Technological Forecasting and Social Change, 157, 120069. https://doi.org/10.1016/ j.techfore.2020.120069

Aprilia, L., \& Wibowo, S. S. (2017). The impact of social capital on Crowdfunding performance. South East Asian Journal of Management, 11(1), 44-57. https://doi.org/10.21002/ seam.v11i1.7737

Ba, S. (2001). Establishing online trust through a community responsibility system. Decision Support Systems, 31(3), 323-336. https:// doi.org/10.1016/S0167-9236(00)00144-5

Belleflamme, P., Lambert, T., \& Schwienbacher, A. (2014). Crowdfunding: Tapping the right crowd. Journal of Business Venturing, 29(5), 585-609. https://doi.org/10.1016/ j.jbusvent.2013.07.003

Bi, S., Liu, Z., \& Usman, K. (2017). The influence of online information on investing decisions of reward-based crowdfunding. Journal of
Business Research, 71, 10-18. https://doi.org/10.1016/ j.jbusres.2016.10.001

Borst, I., Moser, C., \& Ferguson, J. (2017). From friendfunding to crowdfunding: Relevance of relationships, social media, and platform activities to crowdfunding performance. New Media \& Society, 20(4), 1396-1414. https://doi.org/10.1177/1461444817694599

Brynjolfsson, E., \& Smith, M. D. (2000). Frictionless commerce? A comparison of internet and conventional retailers. Management Science, 46(4), 563-585. https://doi.org/10.1287/ mnsc.46.4.563.12061

Bukhari, F. A. S., Usman, S. M., Usman, M., \& Hussain, K. (2020). The effects of creator credibility and backer endorsement in donation crowdfunding campaigns success. Baltic Journal of Management, 15(2), 215-235. https://doi.org/10.1108/BJM-02-2019-0077

Byrnes, J. E. K., Ranganathan, J., Walker, B. L. E., \& Faulkes, Z. (2014). To Crowdfund research, scientists must build an audience for their work. PLoS One, 9(12), 1-29. https://doi.org/10.1371/ journal.pone.0110329

Calic, G., \& Mosakowski, E. (2016). Kicking off social entrepreneurship: How a sustainability orientation influences Crowdfunding success. Journal of Management Studies, 53(5), 738-767. https://doi.org/ 10.1111/joms.12201

Chen, D., Lai, F., \& Lin, Z. (2014). A trust model for online peer-to-peer lending: A lender's perspective. Information Technology and Management, 15(4), 239-254. https://doi.org/10.1007/s10799-0140187-z

Cho, M., \& Kim, G. (2017). A cross-cultural comparative analysis of crowdfunding projects in the United States and South Korea. Computers in Human Behavior, 72, 312-320. https://doi.org/ 10.1016/j.chb.2017.03.013

Chu, S.-C., \& Kim, Y. (2011). Determinants of consumer engagement in electronic word-of-mouth (eWOM) in social networking sites. International Journal of Advertising, 30(1), 47-75. https://doi.org/ 10.2501/IJA-30-1-047-075

Clauss, T., Niemand, T., Kraus, S., Schnetzer, P., \& Brem, A. (2019). Increasing crowdfunding success through social media: The importance of reach and utilisation in reward-nased crowdfunding. International Journal of Innovation Management, 24(03), 2050026. https://doi.org/10.1142/S1363919620500267

Colombo, M. G., Franzoni, C., \& Rossi-Lamastra, C. (2015). Internal social capital and the attraction of early contributions in Crowdfunding. Entrepreneurship Theory and Practice, 39(1), 75100. https://doi.org/10.1111/etap.12118

Currall, S. C., \& Inkpen, A. C. (2006). On the complexity of organizational trust: A multi-level c-evolutionary persptive and guidelines for future research. In R. Bachmann \& A. Zaheer (Eds.), Handbook of trust research (pp. 235-246). Cheltenham: Edward Elgar.

Davies, W. E., \& Giovannetti, E. (2018). Signalling experience \& reciprocity to temper asymmetric information in crowdfunding evidence from 10,000 projects. Technological Forecasting and Social Change, 133,118-131. https://doi.org/10.1016/ j.techfore.2018.03.011

Davis, B. C., Hmieleski, K. M., Webb, J. W., \& Coombs, J. E. (2017). Funders' positive affective reactions to entrepreneurs' crowdfunding pitches: The influence of perceived product creativity and entrepreneurial passion. Journal of Business Venturing, 32(1), 90106. https://doi.org/10.1016/j.jbusvent.2016.10.006

Delhey, J., \& Newton, K. (2003). Who trusts?: The origins of social trust in seven societies. European Societies, 5(2), 93-137. https://doi.org/ $10.1080 / 1461669032000072256$

Delhey, J., \& Newton, K. (2005). Predicting cross-National Levels of social trust: Global pattern or Nordic Exceptionalism? European Sociological Review, 21(4), 311-327. https://doi.org/10.1093/esr/ jci022

Delhey, J., Newton, K., \& Welzel, C. (2011). How general is trust in "Most people"? Solving the radius of trust problem. American 
Sociological Review, 76(5), 786-807. https://doi.org/10.1177/ 0003122411420817

Efrat, K., Gilboa, S., \& Sherman, A. (2019). Relationship approach to crowdfunding: How creators and supporters interaction enhances projects' success. Electronic Markets, 30(4), 899-911. https:// doi.org/10.1007/s12525-019-00391-6

Falk, A., Becker, A., Dohmen, T., Enke, B., Huffman, D., \& Sunde, U. (2018). Global Evidence on Economic Preferences. The Quarterly Journal of Economics, 133(4), 1645-1692. https://doi.org/10.1093/ qje/qjy013

Gefen, D. (2002). Reflections on the dimensions of trust and trustworthiness among online consumers. SIGMIS Database, 33(3), 3853. https://doi.org/10.1145/569905.569910

Gefen, D., Karahanna, E., \& Straub, D. W. (2003). Trust and TAM in online shopping: An integrated model. MIS Quarterly, 27(1), 5190. https://doi.org/10.2307/30036519

Gera, J., \& Kaur, H. (2017). Dynamics of pledge behavior of Crowdfunded projects. International Journal of Information Technology Project Management, 8(1), 72-86. https://doi.org/ 10.4018/978-1-5225-8362-2.ch070

Guo, L., Zhou, D., Chen, Y., \& Huy, R. (2015). Platform strategy and market response impact on the success of Crowdfunding: A Chinese case. Asian Journal of Innovation \& Policy, 4(3), 397-409. https:// doi.org/10.7545/ajip.2015.4.3.397

Haddad, C., \& Hornuf, L. (2019). The emergence of the global fintech market: Economic and technological determinants. Small Business Economics, 53(1), 81-105. https://doi.org/10.1007/s11187-0189991-x

Haerpfer, C., Inglehart, R., Moreno, A., Welzel, C., Kizilova, K., DiezMedrano, J., Lagos, M., Norris, P., Ponarin, E., \& Puranen, B. (2020). World values survey: All rounds - Country-pooled Datafile. Madrid: Spain \& Vienna, Austria Available at: http:// www.worldvaluessurvey.org/WVSDocumentationWVL.jsp.

Hair, J. F. J., Black, W. C., Babin, B. J., \& Anderson, R. E. (2010). Multivariate data analysis (7th ed.). Pearson: Upper Saddle River.

Hobbs, J., Grigore, G., \& Molesworth, M. (2016). Success in the management of crowdfunding projects in the creative industries. Internet Research, 26(1), 146-166. https://doi.org/10.1108/IntR-08-20140202

Hoegen, A., Steininger, D. M., \& Veit, D. (2017). How do investors decide? An interdisciplinary review of decision-making in crowdfunding. Electronic Markets, 28(3), 339-365. https://doi.org/ 10.1007/s12525-017-0269-y

Hofstede, G. (2001). Culture's consequences: Comparing values, behaviors, institutions, and organizations across nations, 2nd. Thousand Oaks: Sage Publications.

Homer, P. M., \& Kahle, L. R. (1990). Source expertise, time of source identification, and involvement in persuasion: An elaborative processing perspective. Journal of Advertising, 19(1), 30-39. https:// doi.org/10.1080/00913367.1990.10673178

Javalgi, R., \& Ramsey, R. (2001). Strategic issues of e-commerce as an alternative global distribution system. International Marketing Review, 18(4), 376-391. https://doi.org/10.1108/ 02651330110398387

Johnson, D., \& Grayson, K. (2005). Cognitive and affective trust in service relationships. Journal of Business Research, 58(4), 500 507. https://doi.org/10.1016/S0148-2963(03)00140-1

Kaartemo, V. (2017). The elements of a successful crowdfunding campaign: A systematic literature review of crowdfunding performance. International Review of Entrepreneurship, 15(3), 291-318.

Kang, M., Gao, Y., Wang, T., \& Zheng, H. (2016). Understanding the determinants of funders' investment intentions on crowdfunding platforms: A trust-based perspective. Industrial Management \& Data Systems, 116(8), 1800-1819. https://doi.org/10.1108/IMDS07-2015-0312
Kim, P. H., Buffart, M., \& Croidieu, G. (2016). TMI: Signaling credible claims in Crowdfunding campaign narratives. Group \& Organization Management, 41(6), 717-750. https://doi.org/ 10.1177/1059601116651181

Kim, Y., \& Peterson, R. A. (2017). A meta-analysis of online trust relationships in E-commerce. Journal of Interactive Marketing, 38, 44 54. https://doi.org/10.1016/j.intmar.2017.01.001

Koch, J.-A., \& Siering, M. (2019). The recipe of successful crowdfunding campaigns. Electronic Markets, 29(4), 661-679. https://doi.org/ 10.1007/s12525-019-00357-8

Kraus, S., Richter, C., Brem, A., Cheng, C.-F., \& Chang, M.-L. (2016). Strategies for reward-based crowdfunding campaigns. Journal of Innovation \& Knowledge, 1(1), 13-23. https://doi.org/10.1016/ j.jik.2016.01.010

Kromidha, E., \& Robson, P. (2016). Social identity and signalling success factors in online crowdfunding. Entrepreneurship \& Regional Development, 28(9-10), 605-629. https://doi.org/10.1080/ 08985626.2016 .1198425

Kshetri, N. (2015). Success of crowd-based online Technology in Fundraising: An institutional perspective. Journal of International Management, 21(2), 100-116. https://doi.org/10.1016/ j.intman.2015.03.004

Kunz, M. M., Bretschneider, U., Erler, M., \& Leimeister, J. M. (2017). An empirical investigation of signaling in reward-based crowdfunding. Electronic Commerce Research, 17(3), 425461. https://doi.org/10.1007/s10660-016-9249-0

Kuppuswamy, V., \& Bayus, B. L. (2018). Crowdfunding creative ideas: The dynamics of project backers. In D. Cumming \& L. Hornuf (Eds.), The economics of Crowdfunding: Startups, portals and investor behavior (pp. 151-182). Cham: Springer International Publishing. https://doi.org/10.1007/978-3-319-66119-3 8

Lawton, k. \& Marom, D. (2012). The Crowdfunding revolution: How to raise venture capital using social meida. New York: NY, McGrawHill.

Lechtenbörger, J., Stahl, F., Volz, V., \& Vossen, G. (2015). Analysing observable success and activity indicators on crowdfunding platforms. International Journal of Web Based Communities, 11(3-4), 264-289. https://doi.org/10.1504/JJWBC.2015.072133

Lee, C. S., \& Ma, L. (2012). News sharing in social media: The effect of gratifications and prior experience. Computers in Human Behavior, 28(2), 331-339. https://doi.org/10.1016/j.chb.2011.10.002

Lee, Y., \& Koo, J. (2016). Can a celebrity serve as an issue-relevant argument in the elaboration likelihood model? Psychology \& Marketing, 33(3), 195-208. https://doi.org/10.1002/mar.20865

Li, E. \& Martin, J. S. (2016). Capital formation and financial intermediation: The role of entrepreneur reputation formation. Journal of Corporate Finance, 59, 185-201. https://doi.org/10.1016/ j.jcorpfin.2016.04.002

Li, J., Chen, X.-P., Kotha, S., \& Fisher, G. (2017). Catching fire and spreading it: A glimpse into displayed entrepreneurial passion in crowdfunding campaigns. Journal of Applied Psychology, 102(7), 1075-1090. https://psycnet.apa.org/doi/10.1037/apl0000217

Liang, T.-P., Wu, S. P.-J., \& Huang, C.-c. (2019). Why funders invest in crowdfunding projects: Role of trust from the dual-process perspective. Information \& Management, 56(1), 70-84. https://doi.org/ 10.1016/j.im.2018.07.002

Liao, C., Zhu, Y., \& Liao, X. (2015). The role of internal and external social capital in crowdfunding: Evidence from China. Revista de Cercetare si Interventie Sociala, 49, 187-2004.

Lim, K. H., Leung, K., Sia, C. L., \& Lee, M. K. O. (2004). Is eCommerce boundary-less? Effects of individualism-collectivism and uncertainty avoidance on internet shopping. Journal of International Business Studies, 35(6), 545-559. https://doi.org/10.1057/ palgrave.jibs. 8400104

Liu, L., Suh, A., \& Wagner, C. (2018). Empathy or perceived credibility? An empirical study on individual donation behavior in charitable 
crowdfunding. Internet Research, 28(3), 623-651. https://doi.org/ 10.1108/IntR-06-2017-0240

Ma, L., Lee, C. S., \& Goh, D. H.-L. (2014). Understanding news sharing in social media : An explanation from the diffusion of innovations theory. Online Information Review, 38(5), 598-615. https://doi.org/ 10.1108/OIR-10-2013-0239

Madrazo-Lemarroy, P., Barajas-Portas, K., \& Labastida, E. T. M. (2019). Analyzing campaign's outcome in reward-based crowdfunding: Social capital as a determinant factor. Internet Research, 29(5), 1171-1189. https://doi.org/10.1108/INTR-03-2018-0115

Makoto, N., Yun, W., \& Norma, S. (2011). How dependent are consumers on others when making their shopping decisions? Journal of Electronic Commerce in Organizations, 9(4), 1-21. https:// doi.org/10.4018/978-1-4666-3622-4.ch011

Mendes-Da-Silva, W., Rossoni, L., Conte, B., Gattaz, C., \& Francisco, E. (2015). The impacts of fundraising periods and geographic distance on financing music production via crowdfunding in Brazil. Journal of Cultural Economics, 40(1), 75-99. https://doi.org/10.1007/ s10824-015-9248-3

Méric, J., Maque, I., \& Brabet, J. (2016). A cartography of the academic literature on crowdfunding. In J. Méric, I. Maque, \& J. Brabet (Eds.), International Perspectiveson Crowdfunding: Positive, Normative and Critical Theory (pp. xxi-xxxvi). Bingley: Emerald Group Publishing Limited.

Mollick, E. (2014). The dynamics of crowdfunding: An exploratory study. Journal of Business Venturing, 29(1), 1-16. https://doi.org/ 10.1016/j.jbusvent.2013.06.005

Mollick, E. (2015). Delivery Rates on Kickstarter December 4, 2015. https://ssrn.com/abstract=2699251.

Moon, Y., \& Hwang, J. (2018). Crowdfunding as an alternative means for funding sustainable appropriate technology: Acceptance determinants of backers. Sustainability, 10(5), 1-18. https://doi.org/ $10.3390 / \mathrm{su} 10051456$

Oh, S., \& Baek, H. (2016). Successful Crowdfunding: Focusing on social interaction and goal achievement motivations. The Journal of Information Systems, 25(4), 141-161. https://doi.org/10.5859/ KAIS.2016.25.4.141

Parhankangas, A., \& Renko, M. (2017). Linguistic style and crowdfunding success among social and commercial entrepreneurs. Journal of Business Venturing, 32(2), 215-236. https://doi.org/ 10.1016/j.jbusvent.2016.11.001

Pavlou, P. A., Liang, H., \& Xue, Y. (2007). Understanding and mitigating uncertainty in online exchange relationships: A principal-agent perspective. MIS Quarterly, 31(1), 105-136. https://doi.org/10.2307/ 25148783

Petty, R. E., \& Cacioppo, J. T. (1986). The Elaboration Likelihood Model of Persuasion. In Communication and persuasion: central and peripheral routes to attitude change (pp. 1-24). New York: Springer.

Pietraszkiewicz, A., Soppe, B., \& Formanowicz, M. (2017). Go pro bono: Prosocial language as a success factor in crowdfunding. Social Psychology, 48(5), 265-278. https://doi.org/10.1027/1864-9335/ a000319

Ryoba, M. J., Qu, S., \& Zhou, Y. (2020). Feature subset selection for predicting the success of crowdfunding project campaigns. Electronic Markets. https://doi.org/10.1007/s12525-020-00398-4

Shneor, R., \& Munim, Z. H. (2019). Reward crowdfunding contribution as planned behaviour: An extended framework. Journal of Business Research, 103, 56-70. https://doi.org/10.1016/ j.jbusres.2019.06.013

Shneor, R., \& Vik, A. A. (2020). Crowdfunding success: A systematic literature review 2010-2017. Baltic Journal of Management, 15(2), 149-182. https://doi.org/10.1108/BJM-04-2019-0148

Short, J. C., Ketchen, D. J., McKenny, A. F., Allison, T. H., \& Ireland, R. D. (2017). Research on crowdfunding: Reviewing the (very recent) past and celebrating the present. Entrepreneurship Theory and Practice, 41(2), 149-160. https://doi.org/10.1111/etap.12270

Siegrist, M., \& Cvetkovich, G. (2000). Perception of hazards: The role of social trust and knowledge. Risk Analysis, 20(5), 713-720. https:// doi.org/10.1111/0272-4332.205064

Siegrist, M., Gutscher, H., \& Earle, T. C. (2005). Perception of risk: The influence of general trust, and general confidence. Journal of Risk Research, 8(2), 145-156. https://doi.org/10.1080/ 1366987032000105315

Skirnevskiy, V., Bendig, D., \& Brettel, M. (2017). The influence of internal social capital on serial Creators' success in Crowdfunding. Entrepreneurship Theory and Practice, 41(2), 209-236. https:// doi.org/10.1111/etap.12272

Steigenberger, N. (2017). Why supporters contribute to reward-based crowdfunding. International Journal of Entrepreneurial Behavior \& Research, 23(2), 336-353. https://doi.org/10.1108/IJEBR-042016-0117

Wang, Z., \& Yang, X. (2019). Understanding backers' funding intention in reward crowdfunding: An elaboration likelihood perspective. Technology in Society, 58, 101149. https://doi.org/10.1016/ j.techsoc.2019.101149

Wessel, M., Thies, F., \& Benlian, A. (2016). The emergence and effects of fake social information: Evidence from crowdfunding. Decision Support Systems, 90, 75-85. https://doi.org/10.1016/ j.dss.2016.06.021

Wessel, M., Thies, F., \& Benlian, A. (2017). Opening the floodgates: The implications of increasing platform openness in Crowdfunding. Journal of Information Technology, 32(4), 344-360. https:// doi.org/10.1057/s41265-017-0040-z

Zhao, L., \& Vinig, T. (2019). Guanxi, trust and reward-based crowdfunding success: A Chinese case. Chinese Management Studies, 14(2), 455-472. https://doi.org/10.1108/CMS-02-20190041

Zheng, H., Hung, J.-L., Qi, Z., \& Xu, B. (2016). The role of trust management in reward-based crowdfunding. Online Information Review, 40(1), 97-118. https://doi.org/10.1108/OIR-04-2015-0099

Zheng, H., Li, D., Wu, J., \& Xu, Y. (2014). The role of multidimensional social capital in crowdfunding: A comparative study in China and US. Information \& Management, 51(4), 488-496. https://doi.org/ 10.1016/j.im.2014.03.003

Zheng, H., Xu, B., Zhang, M., \& Wang, T. (2018). Sponsor's cocreation and psychological ownership in reward-based crowdfunding. Information Systems Journal, 28(6), 1213-1238. https://doi.org/ 10.1111 isj. 12190

Zhou, M., Lu, B., Fan, W., \& Wang, G. A. (2018). Project description and crowdfunding success: An exploratory study. Information Systems Frontiers, 20(2), 259-274. https://doi.org/10.1007/s10796-0169723-1

Ziegler, T., Shneor, R., Wenzlaff, K., Odorović, A., Johanson, D., Hao, R., \& Ryll, L. (2019). Shifting paradigms - the 4th european alternative finance benchmarking report. Cambridge: Cambridge Centre for Alternative Finance.

Ziegler, T., Shneor, R., Wenzlaff, K., Wang, B. W., Kim, J., Odorović, A., Paes, F. F. D. C., Lopez, C., Johanson, D., Suresh, K., Mammadova, L., Adams, N., Luo, D., \& Zhang, B. (2020). The global alternative finance market benchmarking report. Cambridge: Cambridge Centre for Alternative Finance.

Zvilichovsky, D., Danziger, S., \& Steinhart, Y. (2018). Making-the-product-happen: A driver of Crowdfunding participation. Journal of Interactive Marketing, 41, 81-93. https://doi.org/10.1016/ j.intmar.2017.10.002

Publisher's note Springer Nature remains neutral with regard to jurisdictional claims in published maps and institutional affiliations. 